\title{
The development of achievement motivation among students
}

\author{
D.E. Egorov ${ }^{1 *}$, E.V. Egorycheva ${ }^{2}$, and A.A. Pleshakov ${ }^{3}$ \\ ${ }^{1}$ Moscow Polytechnic University, Moscow, Russia \\ ${ }^{2}$ Moscow Polytechnic University, Moscow, Russia \\ ${ }^{3}$ Moscow Polytechnic University, Moscow, Russia
}

\begin{abstract}
There are topics of development achievement motivation among students and learning activity efficiency improvement in elective subjects like physical culture and sport under consideration in this article. The efficiency improvement in elective subjects like physical culture and sport is always of much interest to experts (education, medicine, sociology etc.). Achievement motivation search as a major point of efficiency appears especially relevant. The topics of development achievement motivation have been considered, and the issues prevented to achieve success and reduce the motivation during physical culture and sport subjects have been defined.
\end{abstract}

\section{A problem statement}

The issue of the improvement of quality education at the university depends on many points; the formed motivation is among them, because the efficiency of every activity depends on motivation. If the person is not motivated to a specific activity it will burn out resources as by time so for resources to reach high efficiency. The motivation for development is high capacity and complicated questions.

The efficiency increase of learning activity of students' physical education directly depends on created achievement motivation. The main point of this work is the research of the development of achievement motivation and success fixation.

There is a main issue in the educational system to organize the educational process in the condition of distance and limit of contacts. The creation of this process may be based on digital and IT technology. But any activity should be based on motivation first of all. The motivation is a key factor of efficiency of every activity.

\subsection{The objective of the work}

The purpose of the research is to develop mechanisms for the formation of motivation and achievement attitudes.

\footnotetext{
*Corresponding author: prof-ped.gpa@mail.ru
} 


\section{Results of the research}

Research methods: analysis of literary sources, sociological survey, pedagogical experiment, pedagogical observations. The research was carried out at the Department of Physical Education of the Moscow Polytechnic University.

According to the authors $[1,2,3]$ motivation is the internality which activates, refers and supports the behavior referred to reach special aims. Motivation is the reason for the behavior and capability to satisfy the necessities actively.

The range of factors influence on motivation, few human factors, there are a huge amount of such factors, there are only part of them: I am down on luck at all; I have no right to make mistakes. According to the authors $[4,5,6]$ There is barrier to arrive at a desire point during educational and work activity, consisting of destroyed tenets, appeared on any stages of life and collision to life these tenets fail, but unconsciously the person follows these tenets without analysis and trying to find constructive decision. Such selfdefending beliefs according to research of the authors $[6,7,8]$ do not allow to implement intended things and reach the objects of desire. To discover negative tenets preventing achievement was created the questionnaire including the base tenets, if there were not any respondent could put his her own tenets.

The authors have found out during the anonymous survey that almost all respondents have such tenets concerning various aspects of activity. The major factors for young women and girls are disadvantages of appearance, shortage of funds and "It is not for me" Young men and boys have the following tenets: it is not for me, shortage of funds, I can't make myself do anything.

External forces influence human behavior. According to $[4,9,10]$ external actions influence the character, and the influence depends on the events perception and the same events could be appraised by different people in reverse. Above mentioned inner and external tenets also touch on the educational area. Academic and professional activity is the result of a personal fulfillment area, enlists life satisfaction, demand and the future level of personal fulfilment. All these factors define the prosperity of the personality $[11,3]$.

It is necessary to understand the future position of the student after graduation during the creation of the most efficient methods of motivation. It was held as an opinion pollaccording questionnaire to solve this issue. 138 students of the 3 courses have taken part in the pole. The students were offered to answer the question "Are you confident in employment according to the acquired profession". Results: $69 \%$ of graduates in economic professions, $41 \%$ future specialists of construction branches, $17 \%$ future IT-specialists are not sure about employment and might search for work in other areas.

The question "Do you worry about your future employment?" $70 \%$ polee said that they were anxious about it. Other respondents answered that they did not worry about the situation and had already had the job. Most of the worked students have their job in the area of service, but this situation suits them.

To create a successful tenet according to the authors $[9,12,11]$ is necessary to assign external and internal motives. To create motivation $[12,11]$ it is recommended to take into account the internal motives (to focus on the process and result), related to impulsive learning aim feg. The interest in knowledge and curiosity, the tendency to increase cultural and professional level etc.

According to [7] the creation of motivation including success tends to reach constructive, positive results where the personnel activity is assigned by demand to achieve, that is why it is necessary to make an interest in the activity and the result. According to data $[13,1,12]$ the most valuable results have the people who have an interest in the area they worked, where the interest is the emotional expression of the cognitive need of the person. 
During the pole T. Ehlers questionnaire to learn the achievement motivation the result of the all students (Figure 1).

We can see that medium and heavy medium levels of motivation exceed. According to $[6,14,11]$ the person who is afraid of failure (high defense level), uses little risk, where the failure does not threaten to profile. The motive to avoid failure exceeds and instigates the self-desperation and level of aspiration.

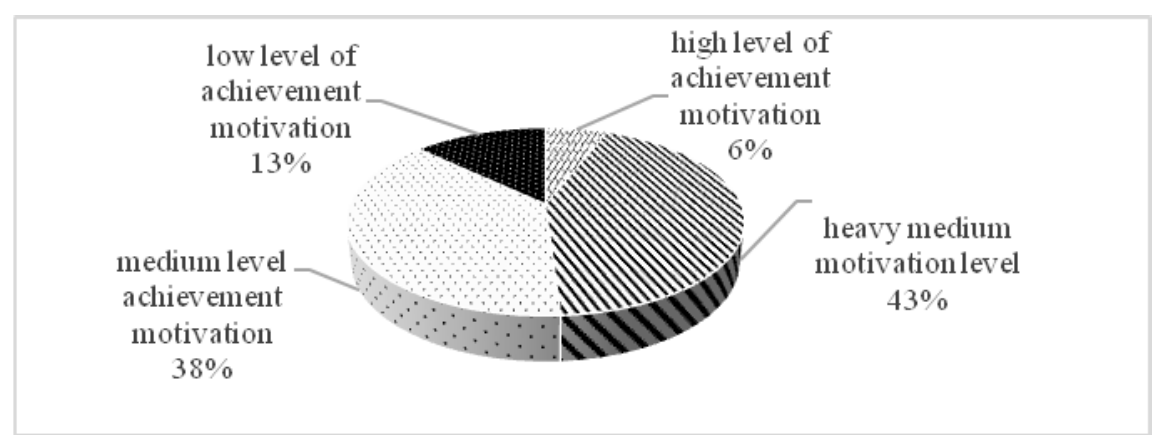

Fig. 1. Level achievement motivation.

According to $[6,14,11]$ the people who have low levels of achievement motivation and the achievements are lower and the level of aspiration is lower. It was confirmed in our further poll, where the students who had a high level of achievement motivation put among the points the development of their own business. So as for low motivated students said that business was not to consider and explain:

- Start large expenses;

- The necessity to devote to business with huge risks and success is uncertain.

According to the pole result young men and women do not consider the elective disciples such as physical culture to achieve, to reach success. For the most of the student's Physical culture and sport, disciplines are considered as an anachronism of Soviet education. They put the example of the USA education and other countries, where students are in class selectively and this discipline is optional.

There was an enquiry to identify the factors to reduce interest to these subjects. They answered that there was interest to them in the lesson where the teacher could not do the exercise in a proper way. Students supposed that the teacher could not show the exercise in a proper way what was the reason for them to do it. Throughout the conversation it was found out that basically the middle age of the teachers in elective disciples physical culture and sport was age related, more than 55 years. Unfortunately, not every teacher can do the exercise in a proper way at such an age. According to the students, the teacher is able to perform the discipline, tell the students about the necessity of it and about prospects for employment activity. If the teacher uses ordinary phrases for them, it is uninterested too. It is the evidence for the students that the teacher is weak in this subject and it is not interesting for the teacher.

It is also important to use modern IT technology to activate the interest during the elective disciplines physical culture and sport study. It is the major factor to stimulate the interest in these classes and increase motivation. Creating motivation and valuable directions are the most important parts for personality development [7, 15].

The attitude to the future profession (job), the motive to choose are very important factors, relating to the success, including further professional study $[4,10]$.

The major factor to create the achievement motivation is to form the tenet for success. According to the data [16] the success of tenet creation or achievement is a key factor for successful motivation activity. To reach a success in elective disciplines physical culture 
and sport can be the achievements in desirable grades as physical form so in shape, to achieve in classification standards etc.

Taking into account the results of the enquiry (178 students, 3 year) we are able to see that quarter of the people have no aims and goals, studying elective disciplines physical culture and sport, it shows the low interest and passive attitude to the subjects. Throughout the conversation, it was realized that everybody knew the profit of physical culture. They knew it almost at school, anything new they would not find out. The low level of knowledge was identified during the test. Only $28 \%$ could tell what the real profit from the subject was. Other students know only main phrases and no proper information about different types of physical activity.

To identify an active teacher position the pole was held. For the 3 year, it was realized that in groups where the teacher personally did any type of sport or sport activity, students went to the classes in elective disciplines physical culture and sport more willingly. Student say that the appearance, look in a good shape, is capable to do the exercise and is able to tell the information are the key factors.

Modern technology is very important for creating the interest and motivation to elective disciplines physical culture and sport, which allow opening valuable practical meaning of the studying material. Modern technology allows reconstructing the situation of reality and seeing the processes happening in the body in different types of sport. The cognitive activity is activated as a result. However, this technological progress would not be so important if we do not use the motivation to study. According to [17] we can see the opinions about low or not formed motivation to the educational process by the students to elective disciplines physical culture and sport.

This opinion is explained by using physical activity, which is not interesting to the students. Educational process based on not taking into account the interests, desires of the student is not interesting for them, and often they find the bypass. In the course of conversation it was settled that one of the bypasses for the classes is the sections in sport clubs and universities. Sometimes the bypass is medical form etc.

The motivation is strongly connected and influences the development personality process; there are some questions that are asked "What do I get if I fulfill my work and what I will not get if I do it in a different way. What will we get if we reach the goal and what we will not get if the goal is not reached". This condition makes us action towards the aim and associated with the results whether our actions either effective or lead to the results $[12,10]$.

Educational activity and its efficiency define the cooperation between student and teacher, what is impossible without motivation and including needs, interests, aims, ideals and motive preparation to action $[4,7]$.

To clarify the knowledge about the elective discipline physical culture and sport influence on professional activity there was made the questionnaire and held an enquiry for 160 students of the $3 \mathrm{~d}$ year (Figure 2).

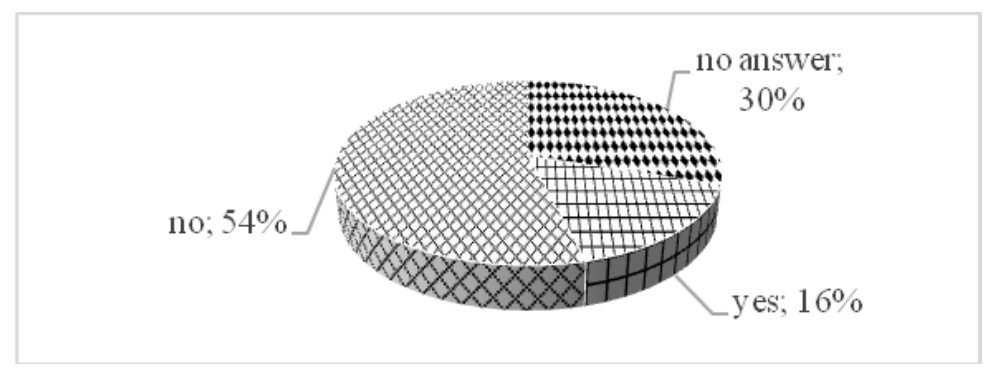

Fig. 2. Question "Do you see into elective disciplines like a success factor for a professional career". 
During the enquiry it was settled, that the success in professional activity is strongly connected to the quality of education at the University, but the main point to succeed is to have useful connections (relationships). The physical training and the health condition is a key factor of efficiency of specialists according to other research [17]. Almost all the student were agree to the argument.

There was an enquiry to define the direction to form a success tenet, where there was a question "Do you help the relatives and close people approval?" Almost all the respondents said that it was very important and always helped to activate the activity.

What do you bother to reach a success? $69 \%$ said about nominal help. It connects to the teachers and close people.

Elective disciplines give the opportunity to choose the type of sport activity according to the interests. During the conversation to create the tenet to success, to achieve the important the team spirit. The results of absorption approved this point, where there was positive or negative spirit in the team. 75 students in 3 year took part.

So the positive spirit team had the activity results $92 \%$, as for negative - only $47 \%$. The efficiency was defined according to test results. The amount of the students and the level of the test are the same.

The support on the teacher's side and close people is also important. The teacher supported the students by using the words "You manage to do this", "You are in a great team and you fulfill everything" and etc. positive phrases. In the other group the teacher observed and did not take any part the results were worth. According to the research we can see that the positive stimulation influences a lot and increase the efficiency. In the group where the teacher told that the students did not manage to do this test it was only for taking part the results were negative "It would be better for him not to tell anything" told the students. the results were the lowest.

To create the motivation is necessary to do the desirable sport. During the enquiry it was clear that ordinary lessons in Physical culture were not interesting for the students, because the structure of the lesson was made without interest of students. So young men select force, game and extremal types of sport activity, as for girls pay more attention to Pilates, yoga, stretching and dances.

There are several questions in this case if there are specialists according to sport activity to select, if there is material basement to organize the educational process. Most of the universities do not have enough material basement to organize the classes according to the chosen sport types and do not have specialists. The range of students have to workout in their free time, but there is no suitable vehicle, specialists and territory in the university, so to organize sport activity is impossible.

Modern technology has a great influence on the achievement motivation, according to the enquiry, $100 \%$ of the respondents would like to have video content during the classes, expanding learning issues. On the lessons elective disciplines in physical culture and sport $60 \%$ respondents prefer media content, where the exercises are done by sportsmen, they can fulfill any exercise and the picture is impressive which increases the interest to the classes.

To stimulate the interest to the classes and different types of sport activity the gadgets are used during the classes (smart watch and bracelets), there are various of functions few heart race fixation, amount of follow steps, and etc. And it is important to listen to different types of music few during the jogging or running, It reduces the monotonous effect. By using the gadgets, the students can see and control the recommended load on their body.

\section{Conclusions}

There are a range of issues is under consideration during the creation of achievement motivation: 
- to form positive attitude to elective discipline physical education and sport;

- teaching stuff are able to present the discipline not less than factor in boosting of physical conditions, but as the tool of professional becoming and success;

- teaching stuff need to inspire the interest to the subject;

- it is necessary to encourage the progress in success;

- it needs to line up the discipline taking into account the interest of the students and take the task of motivation;

- motivation is in heart of obtaining a success (achieve motivation).

It is necessary for stable motivation to stimulate cognitive activity of the students, in other words to create a necessary amount of the knowledge about the influence of the different sport activity on the body. It is achieved during the theoretical course and selfwork of the student, during scientific research work for students. It is unacceptable to formalize the scientific research activity of students.

One of the major issues to develop the achievement motivation to knowledge in different types of sport activity is to form needs of the students $[7,10]$.

According to the research results $[7,13,18,19]$ and analysis it is concluded that to form the tenet for success it is necessary to develop the methods of psychological support. During the educational activity of elective disciplines in physical culture and sport, it is necessary to stimulate the drive towards success.

To increase the efficiency of educational activity $[6,10,14,20]$ :

- to define of negative tenets of the students and work for removal and minimization;

- to create the positive tenets in the furtherance of this goal;

- taking into account by the teacher the personal characteristics of the student, including the level of expertise, necessity and motives;

- the option to choose the type of sport activity and selection justification of type of sport and physical activity for the achievement of specific aims;

- to incite the students to self-goal setting and activity.

The development of the stable motivation to the learning activity requires every teacher focus on forming all components. It is necessary to focus efforts to activate cognitive processes to the subject matter.

\section{References}

1. O.S. Anisimov, Needs and motives: essence and types, Psychology world, 1, 229-236 (2008)

2. I.P. Ilin, Motivation and motives, 298 (2000)

3. V.I. Stepansky, The influence of motivation to reach a success and avoid failures to activity, Psychology questions, 6, 34-37 (1981)

4. M.V. Vorobieva, Motivation 3.0 as a factor to perform professional activity during the academic activity scientific review, The humanities, 3, 44-49 (2015)

5. Pink Drive Daniel, What really motivates us, 32 (2013)

6. M.S. Magomed-Eminov, Personality and extreme life situation, Vestnik MGU. Psychology, 4, 26-35 (1996)

7. R.R. Bibrikh, Motivational aspects of the adaptation of the students to the academic activity, Collection of scientific papers, 17-28 (1990)

8. L.S. Burlachuk, Psychology of life situations, 264 (1998)

9. S.V. Gaponova, G.V. Zikova, The development of competitiveness of personality among a young year in conditions of strict liability and psychological wellness, Tesaraus 5 scientific conference, 16 (2015). 
10. T.G. Khabibova, Students motivation towards educational process VPUIZ, Vestnik Kazan University, 17, 341-343 (2012)

11. T.V. Stepanova, Research to achieve motivation and failure motivation, Vestnik KuzGGU, 6-2 (44), 144-145 (2004)

12. N.A. Ulianova, The importance of professional motivation of high school pupils Innovation projects and programs, Social management academy, 52 (2010)

13. Y.N. Yarovaya, Sociology reasons for motivational behaviour, Education philosophy, 2, 248-254 (2009)

14. A.A. Rean, A.L. Kolominsky, Social pedagogical psychology, 416 (2000)

15. T.E. Lebedeva, IT in practical classes in the university, Graduation today, 8, 49-51 (2007)

16. V.I. Kovalev, Activity and behaviour motives, 191 (1998)

17. S.I. Kramskoy, Increase physical culture knowledge imageand sports in personality, Journal «Diskurs», 12 (14), 58-64 (2017)

18. H. Kheckhauzen, Motivation and activity, 450 (2003)

19. G.D. Babushkin, A.V. Kanatov, E.G. Babushkin, Argument to form the methods of sport motivation of young basketballers, Psychology and pedagogics in Siberia, 58-66 (2000)

20. A.P. Ikonnikova, S.O. Zueva, Psychology difference in time prospects of the students with achieve motivation and avoid motivation, Materials 68 scientific-practical conference of lecturers and students 2 chapters, 74-79 (2018) 